\title{
Paidéia: Management Report - 2015
}

\author{
Manoel Antônio dos Santos ${ }^{1}$ \\ Universidade de São Paulo, \\ Ribeirão Preto-SP, Brazil
}

In this Management Report, we present indicators that give visibility to the editorial management of Paidéia for the year 2015. With the publication of this document, we preserve the tradition of presenting to the scientific community a balance of what the journal has produced in the previous year, making explicit the modus operandi of the processing of the manuscripts in the period.

The dissemination of scientific production is backed by a rigorous peer review process. To systematize information relative to the editorial process, it is possible to place the contribution of Paidéia in the contemporary scenario of scientific publications in the Humanities field, particularly Psychology.

This report is divided into the following sections: Editorial Policy and Arbitration Criteria, Editorial Process - 2015, and Final Considerations.

\section{Editorial Policy and Arbitration Criteria}

Paidéia is a quarterly publication of the Graduate Psychology Program of the Faculty of Philosophy, Sciences and Letters at Ribeirão Preto, University of São Paulo - FFCLRP-USP. Its editorial focus and scope is to publish Psychology related studies. The published articles should fall into the categories: research report, theoretical study, or systematic literature review. These categories are reflected in the results published in this report.

In 2016, Paidéia completes 25 years of existence. Since its founding in August 1991, 63 issues have been published, from volume 1 to 26 , and its collection is fully available through free access provided by the SciELO collection. The issues are conspicuous for their diversity and breadth of topics, as well as for the plurality of methodological designs contained in the articles. The editorial line is generalist, considering the theoreticalmethodological, epistemological and thematic diversity that pervades the Psychology area.

In terms of the classification in the Qualis Journals system, in the area of psychology (Qualis Journals

\footnotetext{
${ }^{1}$ Correspondence address:

Manoel Antônio dos Santos. Universidade de São Paulo. Faculdade de Filosofia, Ciências e Letras de Ribeirão Preto. Departamento de Psicologia. Av. Bandeirantes, 3900. CEP 14040-901. Ribeirão Preto-SP, Brazil. E-mail: masantos@ffclrp.usp.br
}

Commission of Psychology, 2015), Paidéia ascended from the B1 stratum, its status until 2011, to A1, the highest ranking evaluation position, which demonstrates the recognition of the prominent place that the journal occupies within the Brazilian scientific publications. This level of excellence was also verified by another important indicator - in early 2012 the journal was one of the two national publications recognized by the CAPES Support Program for the contribution to the internationalization of scientific journals in the Psychology area. This nomination was sponsored by the Qualis Journals Evaluation Committee and by the Area Evaluation Coordination (Psychology) of CAPES. The Qualis A1 classification and having been chosen by CAPES to be part of the Journal Support Program due to the potential for internationalization are achievements that consecrated Paidéia as one of the leading journals in the current scenario of Psychology in the country.

The prestige given to Paidéia within the scientific community is due to its selective policy of disseminating quality knowledge. Rigorous and thorough assessment is sustained with the support of a highly qualified Editorial Board, structured according to the areas and themes addressed in the articles submitted for consideration. This Council consists of significant names of the academic community, in both the national and international contexts. The processing of the manuscripts is the responsibility of an Editorial Commission composed of Associate Editors, the majority of whom are professors linked to the Graduate Psychology Program of FFCLRP-USP. This commission coordinates the rigorous peer review process, by utilizing ad hoc consultants with recognized competence, who have the task of evaluating and improving the manuscripts submitted for consideration.

To consolidate its visibility at the national and international level, Paidéia is indexed in a solid set of national and international databases (or full text portals) when compared to the other Brazilian journals in the field of Psychology. Our journal has been indexed in the following databases: SciELO - Scientific Electronic Library Online (FAPESP/BIREME), Scopus (Elsevier), PsycINFO - Psychological Abstracts (American Psychological Association), LILACS - Literatura LatinoAmericana e do Caribe em Ciências da Saúde (Centro Latino-americano $y$ de Caribe de Informaciones en 
Ciencias de la Salud), CLASE - Citas Latinoamericanas en Ciências Sociales y Humanidades (Universidad Nacional Autónoma de México), PSICODOC (Colégio Oficial de Psicólogos de Madrid / Universidad Complutense de Madrid), DOAJ - Directory of Open Access Journals, Ulrich's International Periodicals Directory, Catálogo Latindex, IRESIE (Universidad Nacional Autónoma de México), Index-Psi Periódicos (CFP/PUCCAMP), REDALYC - Red de Revistas Científicas de América Latina y el Caribe, España y Portugal, Portal de Revistas da USP (Universidade de São Paulo), ProQuest (CSA) - Databases, EBooks and Technology for Research, EBSCO - Information Services, Cengage Learning, Dialnet (Universidad de La Rioja), OAJI - Open Academic Journals Index, Index Copernicus International (IC Journal Master Listt), HINARI - Access to Research in Health Programme, ResearchGate, EZB - Electronic Journals Library (Universität Regensburg - Germany), HEAL Link - Hellenic Academic Libraries Link, and Socolar (China Educational Publications Import and Export Corporation - CEPIEC). We are currently under evaluation for coverage by the Thomson Reuters group (Web of Science).

The submission of manuscripts is fully computerized, through the Electronic Submission system, provided by SciELO. The journal adopts a blind review evaluation system, which preserves the anonymity of the authors and reviewers. The texts submitted for consideration must primarily fall within the research report category. In each issue approximately 13 original research articles are published. From 2012, the following types of contributions were no longer accepted: reports of professional experience, brief communications, technical notes, and book reviews. As part of the new editorial policy of the journal, the Editorial Board decided to invest heavily in attracting articles that give visibility to research results derived from original empirical studies with quantitative or qualitative designs. The potential to make an impact in the area of knowledge is also a criterion for the selection of the manuscripts for publication. To be selected for publication, the manuscripts must be of international interest, rather than just local.

With regard to financing sources, Paidéia has relied on support from financial resources received annually from the Periodical Scientific Publications Support Program of USP and from the Scientific Publications Support Program of the National Council for Scientific and Technological Development (CNPq), as well as the support of the Graduate Psychology Program of FFCLRP-USP.

The publication standards are included at the end of each issue, which are available online in the languages: Portuguese, English, and Spanish. Those standards (Instructions to the Authors) are available on the SciELO page (http://www.scielo.br/paideia). The final issue of each volume provides the list of ad hoc evaluators, who contributed to the essential task of reviewing the manuscripts during the year.

The printed version of Paidéia is distributed free- of-charge to approximately 160 libraries in Brazilian public universities linked to the Brazilian Network of Psychology Libraries - ReBAP. In this way, the issues are made available for the undergraduate Psychology courses and some Education courses in Brazil, as well as in other countries, such as Portugal, Spain, Mexico, Poland, the UK and the USA. This means that, three times a year, examples are sent to the higher education institutions of many Brazilian states and some abroad, as well as to Graduate Programs in the fields of Psychology and Education. Exchanges are also maintained with Brazilian and international Psychology and Health journals. The final issue of each volume is also sent to all the ad hoc consultants who collaborated with the journal during the year, in recognition of the collaboration provided. In this final issue (printed version) of each volume, we provide a list of ad hoc consultants who worked with the journal during the current year. It is a way of thanking those who contributed with the review of the manuscripts submitted to the journal.

Regarding the manuscript arbitration process, Paidéia adopts the mechanism of double-blind review by peers of recognized competence within the scientific community. Thus, the identities of the authors and of the ad hoc consultants are kept in strict confidentiality. The texts submitted for review should be in accordance with the guidelines of the publication standards and may be accepted or rejected by the Editorial Board, based on the recommendations of its members and the ad hoc consultants selected to enhance the evaluation process.

In relation to the availability of the content, Paidéia adopts the Creative Commons License, Attribution Noncommercial CC BY-NC. With this license it is permitted to access, download, copy, print, share, reuse, and distribute the articles, provided it is for noncommercial use and includes the citation of the source, giving appropriate credit to the journal. In such cases, no permission is required from the authors or the publishers.

The complete collection of the journal, including past issues, is available on the SciELO site, from the conversion of the archives to the standard used by this database, thus increasing the visibility of the articles published, in accordance with the policy of free and universal access to the contents of the journal.

Another aspect that distinguishes Paidéia in the scenario of Psychology publications is the systematic and periodic provision of information regarding the management process of the journal. In the first issue of each volume/year we publish a Management Report, in which we seek to provide visibility and transparency to the work consolidated in the previous year. This document contains objective indicators to measure the progress of the journal, such as the processing time of the manuscripts, the origin of the authors who have their articles published, and the institutional origins of the reviewers/ad hoc consultants, among other topics of interest (Santos, 2013, 2014, 2015). 


\section{Editorial Process - 2015}

When considering the editorial process of Paidéia in 2015 , it can be observed that the average processing time of the manuscripts was approximately 6 months. One year earlier (2014), the mean processing time was 8 months, revealing considerable improvement. The journal also improved the mean time between the submission and the first assessment of the manuscript (4 months on average). In this year, the journal received 142 new manuscripts, of which 19 were approved, 66 rejected and 57 were still in the evaluation process in November of 2015, when this report was written (Table 1). Considering the manuscripts for which the editorial process was terminated in $2015(n=85)$, the journal approved $22.4 \%$ and rejected $77.6 \%$.

Table 1

Editorial Situation of the Manuscripts Submitted to Paidéia in 2015

\begin{tabular}{lc}
\hline Final decision & $n$ \\
\hline Received (Total) & 142 \\
\hline Approved & 19 \\
Rejected & 66 \\
In the editorial process & 57 \\
\hline $\begin{array}{l}\text { Note. Mean time between submission and publication in 2015 =8 } \\
\text { months. }\end{array}$
\end{tabular}

The number of articles submitted in 2015 (142) was higher than that observed in 2014 (127 manuscripts), an increase by approximately $11 \%$ over the previous year. This increase suggests that the authors fully assimilated the great modifications Paidéia implemented in 2013 (full implementation of the new publication standards of the journal, which included, in addition to more stringent quality criteria, the system of publication in the English language, with the financial costs of the translation, performed by qualified experts, covered exclusively by the authors).

Manuscripts submitted in 2015 were classified in the following categories: (a) Research report (85\%); (b) Theoretical study (4.7\%); (c) Systematic literature review $(10.3 \%)$, as presented in Table 2 .

Table 2

Category of the Manuscripts Submitted to Paidéia in 2015

\begin{tabular}{lcc}
\hline Type of manuscript & $n$ & $\%$ \\
\hline Research report & 123 & 86.6 \\
Systematic literature review & 12 & 8.4 \\
Theoretical study & 7 & 5.0 \\
Total & 142 & 100.0 \\
\hline
\end{tabular}

In 2015, in volume 25 (issues 60, 61 and 62), 38 articles and one theoretical study were published, as well as two editorials and one management report. The publications were classified into the following categories: (a) Research report (92.3\%) and (b) Systematic literature review (7.7\%), as presented in Table 3.

Table 3

Category of the Manuscripts Published in Paidéia in 2015

\begin{tabular}{lcc}
\hline Type of manuscript & $n$ & $\%$ \\
\hline Research report & 38 & 97.5 \\
Systematic literature review & - & - \\
Theoretical study & 1 & 2.5 \\
Total & 39 & 100.0 \\
\hline
\end{tabular}

Figure 1 shows the evolution of the number of manuscripts submitted and their fate in the triennium 2013-2015. In 2015, there was an increase in the number of new manuscripts submitted to Paidéia. The refusal rate remained stable. The rate of approved manuscripts also remained stable, which highlights the rigorous analysis of the manuscripts selected for publication.

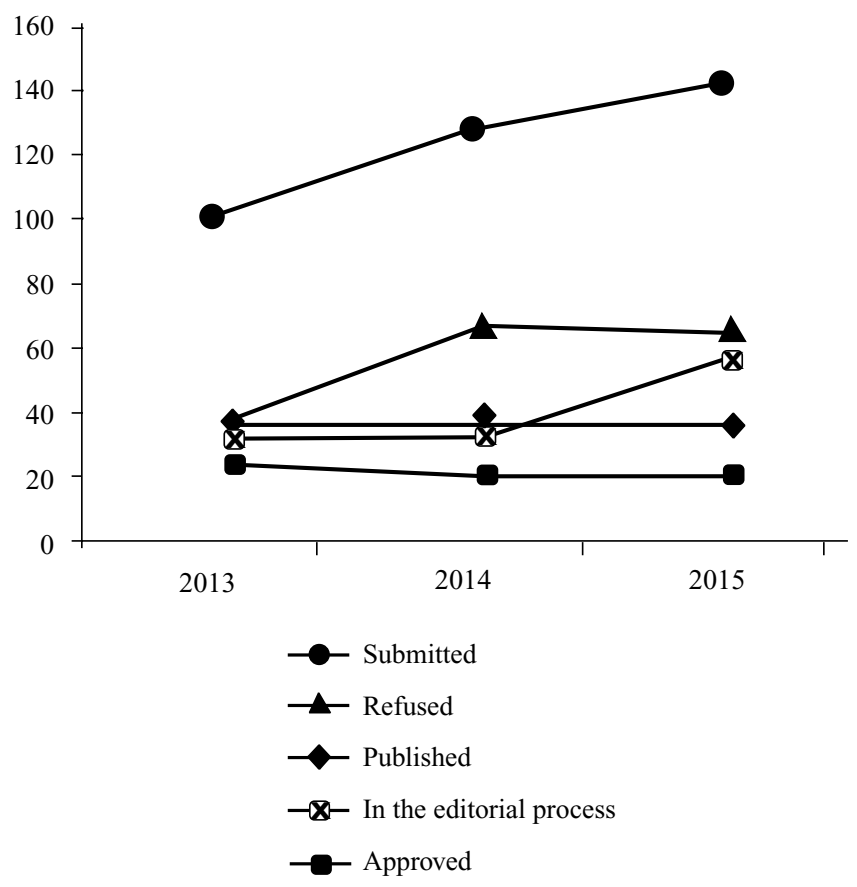

Figure 1. Number of manuscripts submitted to Paidéia and their editorial outcome in the triennium 2013-2015.

Regarding the institutional affiliation of the authors, Table 4 shows that Paidéia published articles originating from 26 Brazilian universities/colleges/institutes, with a predominance of the Universidade Federal do Rio Grande do Sul. There was a reasonable increase in the amount of articles with authors affiliated with international institutions, mainly from Portugal. It should be noted that the authors of the published articles are linked to a variety of higher education institutions, public, private and confessional, of various states of the Brazilian federation and abroad. In 2015, there was a predominance of federal over state universities. 
Table 4

Institutional Origin of the Authors Who Published in Paidéia in 2015

\begin{tabular}{|c|c|c|}
\hline National institutions & $n$ & $\%$ \\
\hline Universidade Federal do Rio Grande do Sul - RS & 16 & 17.6 \\
\hline Universidade de São Paulo - SP & 11 & 12.0 \\
\hline Universidade São Francisco - SP & 7 & 7.7 \\
\hline $\begin{array}{l}\text { Universidade Federal de Ciências da Saúde de } \\
\text { Porto Alegre - RS }\end{array}$ & 6 & 6.6 \\
\hline Universidade Salgado de Oliveira - RJ & 6 & 6.6 \\
\hline Pontifícia Universidade Católica - GO, PR & 5 & 5.5 \\
\hline Universidade Federal de São Carlos - SP & 5 & 5.5 \\
\hline Universidade Federal de Santa Catarina - SC & 4 & 4.4 \\
\hline Universidade Federal de São Paulo - SP & 4 & 4.4 \\
\hline Universidade Estadual de Londrina - PR & 3 & 3.3 \\
\hline Universidade Federal do Rio Grande do Norte - RN & 3 & 3.3 \\
\hline Universidade Federal do Pará - PA & 3 & 3.3 \\
\hline Universidade do Vale do Rio dos Sinos - RS & 2 & 2.2 \\
\hline Universidade Estadual Paulista - SP & 2 & 2.2 \\
\hline Universidade Federal da Paraíba - PB & 2 & 2.2 \\
\hline Universidade Federal de Goiás - GO & 2 & 2.2 \\
\hline Agência Nacional de Aviação Civil - DF & 1 & 1.1 \\
\hline Universidade de Brasília - DF & 1 & 1.1 \\
\hline Universidade Estadual de Campinas - SP & 1 & 1.1 \\
\hline Universidade Presbiteriana Mackenzie - SP & 1 & 1.1 \\
\hline Universidade Federal do Rio de Janeiro - RJ & 1 & 1.1 \\
\hline Universidade Federal de Pernambuco - PE & 1 & 1.1 \\
\hline Universidade do Estado de Santa Catarina - SC & 1 & 1.1 \\
\hline Universidade Federal do ABC - SP & 1 & 1.1 \\
\hline Universidade Federal do Recôncavo da Bahia - BA & 1 & 1.1 \\
\hline Universidade Tuiuti do Paraná - PR & 1 & 1.1 \\
\hline Total & 91 & 100 \\
\hline International institutions & $n$ & $\%$ \\
\hline Universidade do Minho, Portugal & 6 & 28.4 \\
\hline University of North Carolina, USA & 4 & 19.0 \\
\hline Universidade do Algarve, Portugal & 2 & 9.4 \\
\hline University of Pittsburgh, USA & 1 & 4.8 \\
\hline Indiana University South Bend, USA & 1 & 4.8 \\
\hline Centro de Psicologia da Força Aérea, Portugal & 1 & 4.8 \\
\hline $\begin{array}{l}\text { Instituto Superior de Línguas e Administração, } \\
\text { Portugal }\end{array}$ & 1 & 4.8 \\
\hline Universidade Católica Portuguesa, Portugal & 1 & 4.8 \\
\hline Universidade de Lisboa, Portugal & 1 & 4.8 \\
\hline $\begin{array}{l}\text { Universidade de Trás-os-Montes e Alto Douro, } \\
\text { Portugal }\end{array}$ & 1 & 4.8 \\
\hline Universidade do Porto, Portugal & 1 & 4.8 \\
\hline Universidade Europeia, Portugal & 1 & 4.8 \\
\hline Total & 21 & 100 \\
\hline
\end{tabular}

Table 5 presents data relating to the body of ad hoc consultants of Paidéia, highlighting the country and region of origin.

Table 5

Distribution of the ad hoc Consultants of Paidéia According to Their Geographic Origin $(N=184)$

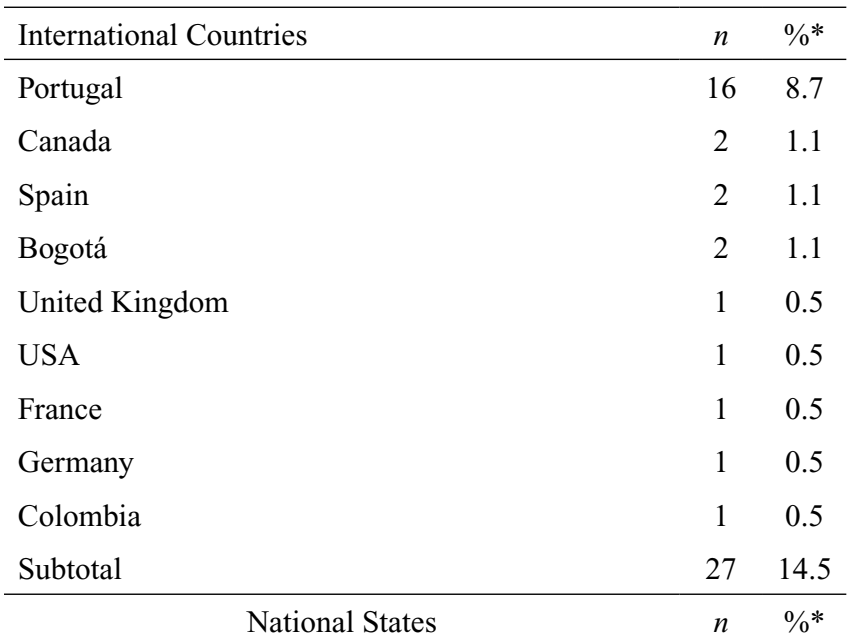

Southeastern Region

São Paulo

$84 \quad 45.5$

Minas Gerais

$12 \quad 6.4$

Rio de Janeiro

$11 \quad 6.1$

Espírito Santo

$4 \quad 2.3$

Subtotal

11160.3

Southern Region

Rio Grande do Sul $\quad 15 \quad 8.1$

Paraná

Santa Catarina

$3 \quad 1.7$

Subtotal

$24 \quad 13.1$

Central-Western Region

$\begin{array}{lll}\text { Federal District } & 6 & 3.3\end{array}$

Goiás

10.5

Mato Grosso

$1 \quad 0.5$

Subtotal

$8 \quad 4.3$

Northeastern Region

Bahia

$4 \quad 2.3$

Sergipe

$3 \quad 1.7$

Paraíba

$2 \quad 1.1$

Pernambuco

10.5

$\begin{array}{lll}\text { Rio Grande do Norte } & 1 & 0.5\end{array}$

Subtotal

$11 \quad 6.1$

Northern Region

Pará

$3 \quad 1.7$

Subtotal

$3 \quad 1.7$

* Calculation based on the total of 184 advisors who collaborated with the journal until November, 2015. 
Regarding the origins of the ad hoc consultants, the predominance should be noted of reviewers from the universities of São Paulo (45.5\%) which, added to the evaluators from other institutions within the Southeastern, totaled $60.3 \%$ of the body of reviewers. The Southern region contributed $13.1 \%$ of the $a d$ hoc evaluators; the Central-Western region contributed 4.3\%; while the Northeastern region had a participation of $6.1 \%$ and the Northern region $1.7 \%$.

These results show that the number of evaluators from the Southeastern had a slight increase when compared to 2014 (57.8\%). Thus, a slight decrease was found for the Southern reviewers (from $17.4 \%$ in 2014 to $13.1 \%$ in 2015), but a slight increase could also be perceived in the Northeastern region (from $4.8 \%$ in 2014 to $6.1 \%$ in 2015). Furthermore, the important collaboration of international evaluators can be noted, $14.5 \%$ (Table 5).

Figure 2 shows the percentile distribution of the ad hoc consultants according to geographic origin.

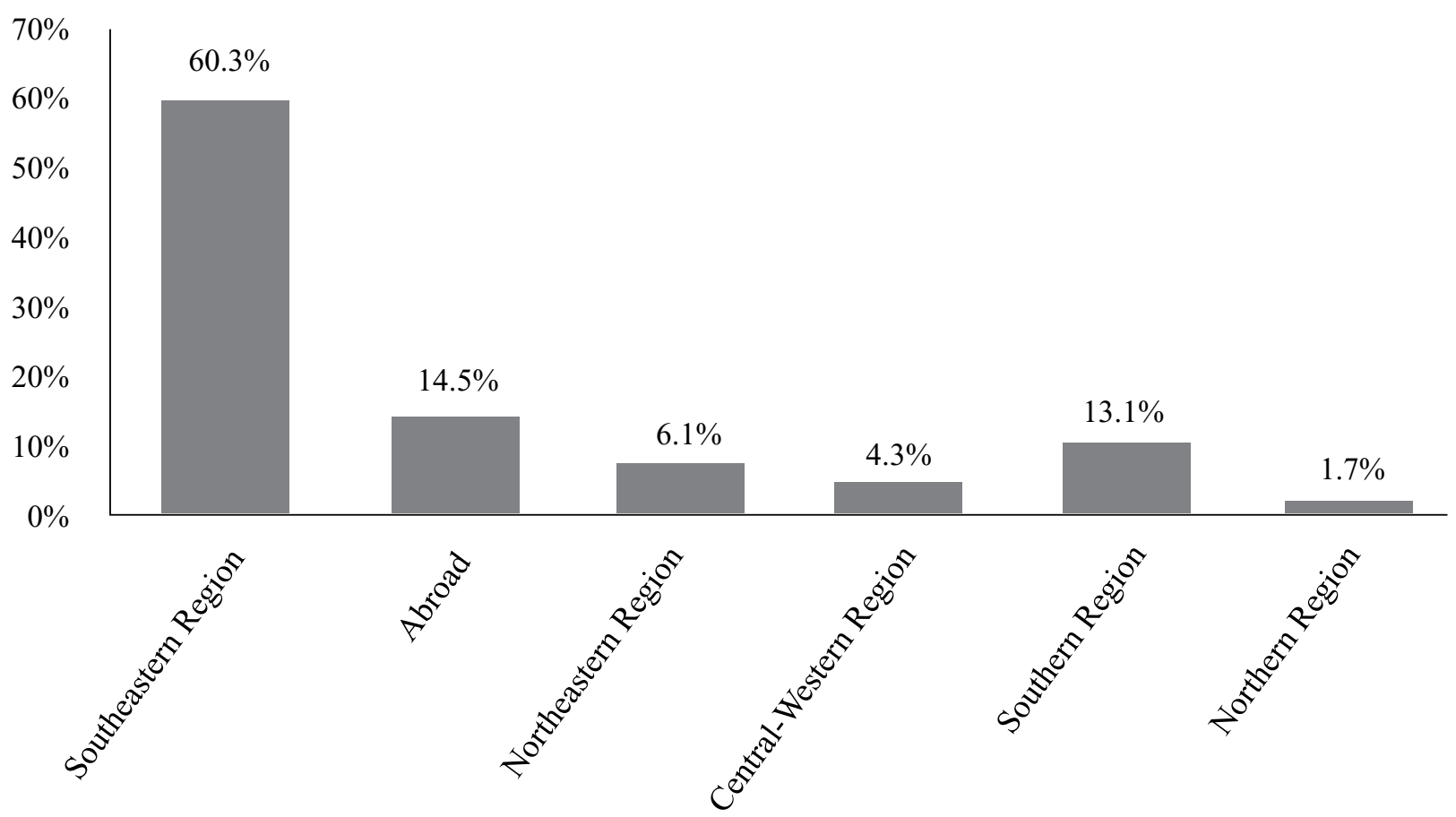

Figure 2. Distribution of the ad hoc consultants who collaborated with Paidéia in 2015 according to their region of origin.

\section{Final Considerations}

In recent years, Paidéia has worked hard to consolidate itself as one of the most prestigious Psychology publications in the Brazilian context. With true entrepreneurial spirit, coordinated actions have been implemented to create objective conditions for the internationalization of the journal, which enhanced the visibility of the articles published.

This management report systematizes information that permits the mapping of the framework of the editorial processing of the manuscripts submitted to the Paidéia during the year 2015. Comparison of the data accumulated over the last three years shows that the journal has gradually and consistently strengthened its editorial process, establishing itself as a unifying space for the knowledge produced in the field of Psychology. However, some fragilities need to be considered, such as the limited number of international collaborations and the concentration of $a d$ hoc consultants in the Southeastern states. The low percentage of articles from foreign authors is a limitation as well. Overcoming these challenges requires the adoption of specific strategies.

One positive aspect to be highlighted in this report is the adoption of the publication of the full text of the articles in English in 2012, which gives greater international visibility to the articles published in the journal. The journal has ensured its inclusion in new international indexes, which contributes to the internationalization efforts.

Another positive point is that the rate of "endogeneity" of the journal (articles from authors of the University of São Paulo) - $12 \%$ of the articles published in 2015 - although it had a slight increase, remained stable, when considering the historical series. This rate was 9.5\% in 2014 (Santos, 2015) and $9.9 \%$ in 2013 (Santos, 2014). In other words, Paidéia proves to be a journal that is truly open to the Brazilian scientific community and, in recent years, increasingly oriented towards the international community, according to the guidelines of our Action Plan agreed upon with CAPEs in 2011-2012, when the journal ran for and won a Call aimed at levering the internationalization of the scientific journals of all knowledge areas. Paidéia won the Call, recognizing its excellent contribution in the editorial context. Since then, the journal has honored all of the commitments assumed in that Action Plan, rapidly turning into an international publication.

As a result of the continuing efforts that have been 
systematically undertaken over the last few years, Paidéia today occupies a prominent place among the publications in the field of psychology, among the six national journals in the area classified as A1 (Qualis Journals Commission of Psychology, 2015). The introduction of the online submission represented a substantial gain for the organization and management of the flow of information, helping to decrease the time of publication, however, is still far from ideal and should be continuously improved. Therefore, as from February, 2016, Paidéia will start using a new online editorial management system called ScholarOne. Investments to increase the visibility of the journal in the international context are needed, to attract articles from foreign researchers, to amplify the indexation in international databases, and to enhance the bibliometric indicators.

Regarding the communication of science, it must be remembered that the publication may be through various means, with scientific journals highlighted due to quality control, greater credibility, consistency, and visibility of information. Scientific knowledge is mainly derived from original research, submitted to the peer review process and published in an indexed journal, with attention to the use and impact of the information conveyed. Being indexed in specialized or multidisciplinary databases is the seal of quality of a journal.

The issue of the native language being privileged in the publication remains a constraint to increasing the visibility of articles published by the national journals. For years Paidéia has been publishing abstracts in Portuguese, English and Spanish, which always constituted a difference compared to other journals in the field of psychology, which traditionally only require the abstract in Portuguese and English. In 2012, we implemented the bilingual publication of articles, i.e., we provided the electronic library (SciELO) with the full versions in Portuguese and English, following the example of journals from other fields of knowledge. From the second issue of 2013, the articles began to be published in English only, in the printed version as well as the online version.

These significant advances have required increased efforts from the Editorial Commission to guarantee the technical quality of the English language. All manuscripts are translated - or reviewed - and certified by a Committee of Translators accredited by the journal. This Committee includes professional specialized in scientific publications and renowned international companies that have gained prestige in the scientific publication market. In this way, we are gradually fulfilling the goals established so that Paidéia can contribute to the production of knowledge in Psychology that can achieve the desirable international levels of excellence and be profiled with other more advanced areas of knowledge.

Considering the great increase in the national scientific production in recent years, due to a stimulus policy that is unfortunately often confused with the deleterious productivism resulting from the pressure to publish, it is highly desirable for national journals to give greater transparency to their publishing processes. Thus, this Management Report complies with the social mission of returning to society the result of public investments that have been allocated in recent years to the field of science and technology. Finally, the scientific journals play an important role in evaluating the quality and dissemination of the knowledge produced in the area of Psychology. They are the principle means of publication and also the most prestigious and credible.

\section{References}

Comissão Qualis Periódico da Psicologia. (2015). Qualis periódico da psicologia: Atualização 2015. Brasília, DF: Coordenação de Aperfeiçoamento de Pessoal de Nível Superior. Retrieved from https://www.capes.gov. br/images/stories/download/avaliacaotrienal/Docs_ de_area/qualis/relatorio_atualizacao_qualis_2015_ psicologia_23_06_15.pdf

Santos, M. A. (2013). Paidéia: Relatório de gestão - 2012. Paidéia (Ribeirão Preto), 23(54), 3-7. doi:10.1590/198243272354201302

Santos, M. A. (2014). Paidéia: Management report - 2013. Paidéia (Ribeirão Preto), 24(57), 5-9. doi:10.1590/198243272457201402

Santos, M. A. (2015). Paidéia: Management report - 2014. Paidéia (Ribeirão Preto), 25(60), 3-8. doi:10.1590/198243272560201502

Manoel Antônio dos Santos is an Associate Professor of the Faculdade de Filosofia, Ciências e Letras de Ribeirão Preto at the Universidade de São Paulo, and Editor-in-Chief of Paidéia.

How to cite this management report:

Santos, M. A. (2016). Paidéia: Management report - 2015. Paidéia (Ribeirão Preto), 26(63), 1-6. doi:10.1590/198243272663201601 